\title{
Gamma Distribution
}

National Cancer Institute

\section{Source}

National Cancer Institute. Gamma Distribution. NCI Thesaurus. Code C53223.

A two-parameter family of continuous probability distributions, with a scale parameter theta and a shape parameter $\mathrm{k}$. 